\title{
Phosphorus Removal from Urban Wastewater via Chemical and Combined Treatment against eutrophication of Receiving Environments
}

\author{
Nawel Nedjah and Nabila Laskri \\ Preparatory School of Science and Technology (EPST) 23000 Annaba, Algeria \\ nedjah23nawel@gmail.com (N.Nedjah)laskri_n@yahoo.fr (N.Laskri)
}

\begin{abstract}
This research work aims at highlighting the importance of wastewater treatment generally and removing phosphorus from these waters specifically, in order to preserve our environment. Reducing the rejected quantity of phosphorus, nutrient element, in the receiving environments, enables the restriction of the phenomenon of water streams eutrophication. This is the primary objective of our research. Both the chemical and biological treatments are recognized as effective for phosphorus removal from waste water. In our study, we worked on phosphorus removal from urban wastewater through three treatments types: chemical, biological, and a combined one. The findings of the chemical treatment demonstrated a good treatment efficiency of the organic matter: $95 \%$ of DCO and 88\% of phosphorus; as per the biological treatment: $60 \%$ of DCO and 49\% of phosphorus were found. A further treatment has been conducted through combining the first couple of treatments. This combination method seeks to find the optimal dose of the different conventional coagulants namely lime, ferric chloride and aluminum sulfate. The combined treatment resulted in a better phosphorus removal efficiency: $83 \%$ of phosphorus and 96\% of DCO. The obtained results proved to be highly encouraging and incite the responsible / heads of STEP to adapt and apply this type of treatment which revealed to be an appropriate purification technique of wastewater.
\end{abstract}

Keywords: Wastewater, phosphorus, nutrient, eutrophication, chemical treatment, biological treatment

\section{Introduction}

Despite its virtues as an essential element to life, the phosphorus has also a reputation as polluting. In rural areas, it trickles down regularly agricultural fields in the waters, and in the urban areas, it comes from the wastewater, the main ingredient of human excreta from the toilet flush. In both cases [1], the phosphorus can increase the levels of concentration of nutrients from the place, causing the pluses of algae in lakes and rivers, where it accumulates: a process called eutrophication [2].

These excessive growths of algae can potentially reduce the available oxygen in the water, to the point that some species of fish can no longer survive. It is this which afflicted the Lake Erie in 1970's, which attracted the attention of David Schindler, a biologist at the University of Alberta. By taking a small lake in northern Ontario, it divided it into 2 and demonstrated that it was the phosphate in detergents which came from the municipal wastewater which were the main reasons of what afflicted the Lake Erie [3]. The manufacturers of detergents were then motivated to reduce the quantities of phosphates in their products, which has decreased eutrophication of the lake [4].

The growth of the urban population and the development of activities lead to an excessive exploitation of aquifers and their contamination as well as a significant 
increase of discharges in the natural environment, and this, well beyond the selfpurification capacity of the wadis [5].

The elimination of phosphorus, or "phosphate removal", can be carried out by way of physico-chemical or biological [6].

As per the physico-chemical treatments, the addition of reagents, such as the salts of iron or aluminum, allows to obtain a precipitation of insoluble phosphates and their elimination by decantation. These techniques, the most currently used, eliminate between $80 \%$ and $90 \%$ of the phosphorus, but engender a significant production of sludge [7].

The biological phosphate removal involves the accumulation of phosphorus in the bacterial cultures of sludge. The mechanisms of the biological phosphate removal are relatively complex and their performance variable (in particular according to the carbonaceous pollution and nitrates present in the wastewater) [8]. The average yield is approximately $60 \%$. In the large sewage treatment facilities, this process is often paired with a physico -chemical phosphate removal, to achieve the levels of discharges required [9].

\section{Methods and Materials}

\subsection{Wastewater Sampling}

Wastewater samples were collected (during summer) from the station of treatment by activated sludge situate in the town of Annaba - Algeria- This station discharges its wastewater rejections to the sea [10]. The samples were collected in polyethylene bottles and kept in a humid dark place; they have been the subject of a direct measurement of physico-chemical parameters (temperature, $\mathrm{pH}, \mathrm{COD}$ and $\mathrm{P}$ ).

The raw water is characterized by the following physicochemical parameters:

- $\mathrm{pH}=7,12$;

- $\quad$ Turb $=17,4$ NTU;

- $\quad \mathrm{DCO}=50,928 \mathrm{mg} / \mathrm{l}$;

- $\quad \mathrm{P}=0,989 \mathrm{mg} / \mathrm{l}$.

This wastewater has been the preferred substrate for the coagulation-flocculation optimization tests by employing the usual conventional coagulants that proved their purifying ability such as aluminum sulfate, ferric chloride and finally lime [11].

Several tests were carried out in the laboratory and allowed to set the agitation speed at $200 \mathrm{tr} / \mathrm{mim}$ for an optimal time of $15 \mathrm{~min}$, these optimal operating conditions are met during the chemical treatment by coagulation- flocculation. We start this experimental work by determining the optimal dose of each selected coagulant.

\subsection{Chemical Analyses}

A representative sample of the wastewater is taken each time to perform chemical analysis. The physico chemical analyses used are [12]:

- $p H$

The measurement of $\mathrm{pH}( \pm 0.1 \mathrm{pH}$ unit $)$ is done directly by reading on a $\mathrm{pH}$-meter to combined electrode.

- $\quad$ Turbidity

The measure must be determined as quickly as possible. The standardized method Afnor NF U 44-171, consists of a measure of the turbidity with a turbidity apparatus.

\section{- Phosphorous determination}

Phosphorus measurement is done using the method of ammonium molybdate at 380 nm. 
A mass around $50 \pm 0.1 \mathrm{~g}$ is calcined at $550{ }^{\circ} \mathrm{C}$, for 2 hours in a furnace (NF U 44160).

- Chemical oxygen demand (COD) Measurement with the assistance of equipment and by spectrophotometry UV-VIS.

\section{Results and Discussion}

\subsection{The Chemical Treatment}

The results of the laboratory tests clearly show that when adding a dose of $150 \mathrm{mg} / \mathrm{l}$ and $200 \mathrm{mg} / \mathrm{l}$ of aluminum sulfate, gives a very low concentration of phosphorus and turbidity with a neutral $\mathrm{pH}$, Figure $1-\mathrm{a}$ and Figure 1-b shows the result, the wastewater has a good removal efficiency of phosphorus.

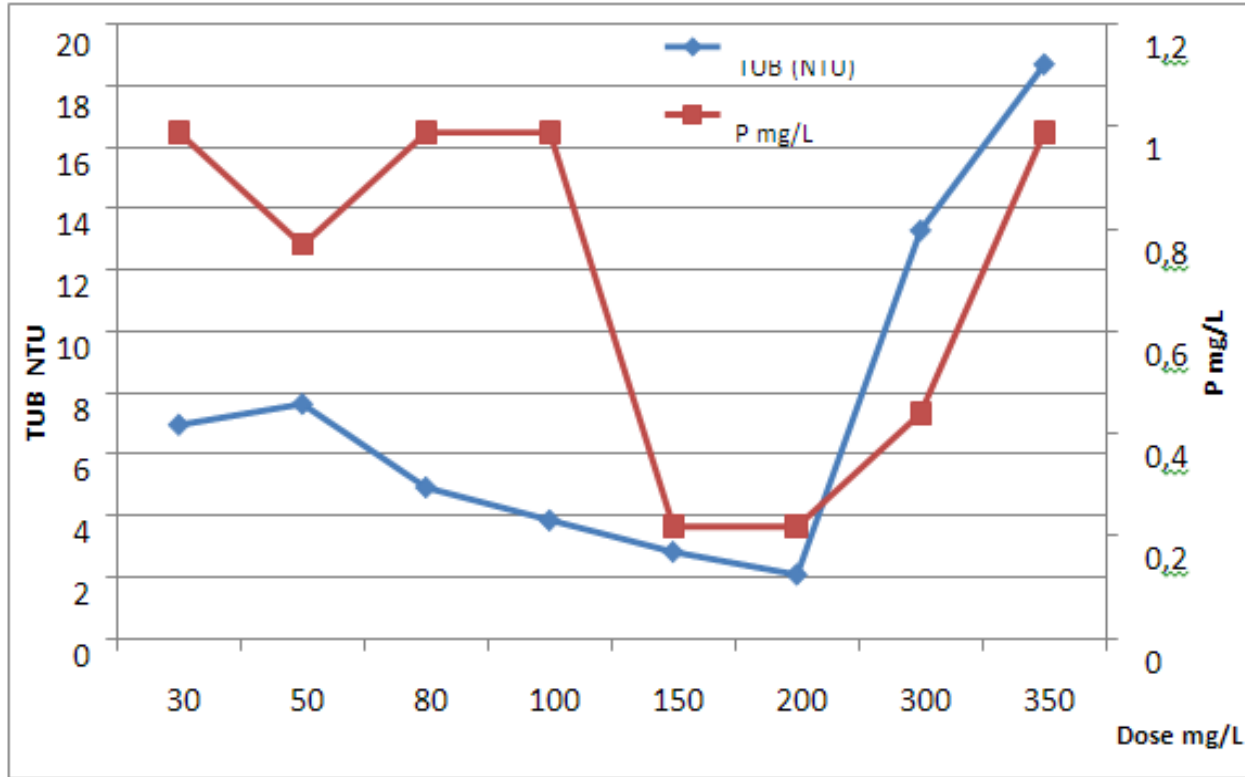

Figure 1-a. Dose Optimale of Aluminum Sulfate

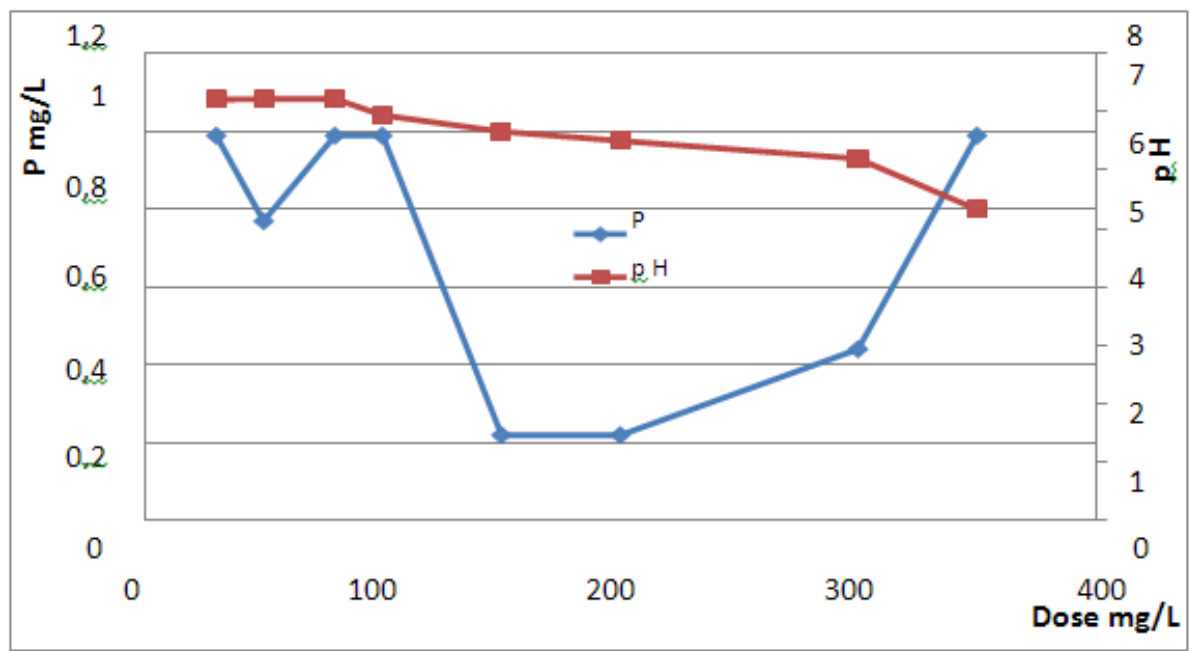

Figure 1-b. Dose optimal of Aluminum Sulfate 
In the case of ferric chloride the optimal dose will be $200 \mathrm{mg} / 1$, this dose gives a very low concentration of phosphorus and turbidity with a neutral $\mathrm{pH}$, as shown in Figure 2-a and Figure 2-b, chemical treatment gave maximum phosphorus removal efficiency.

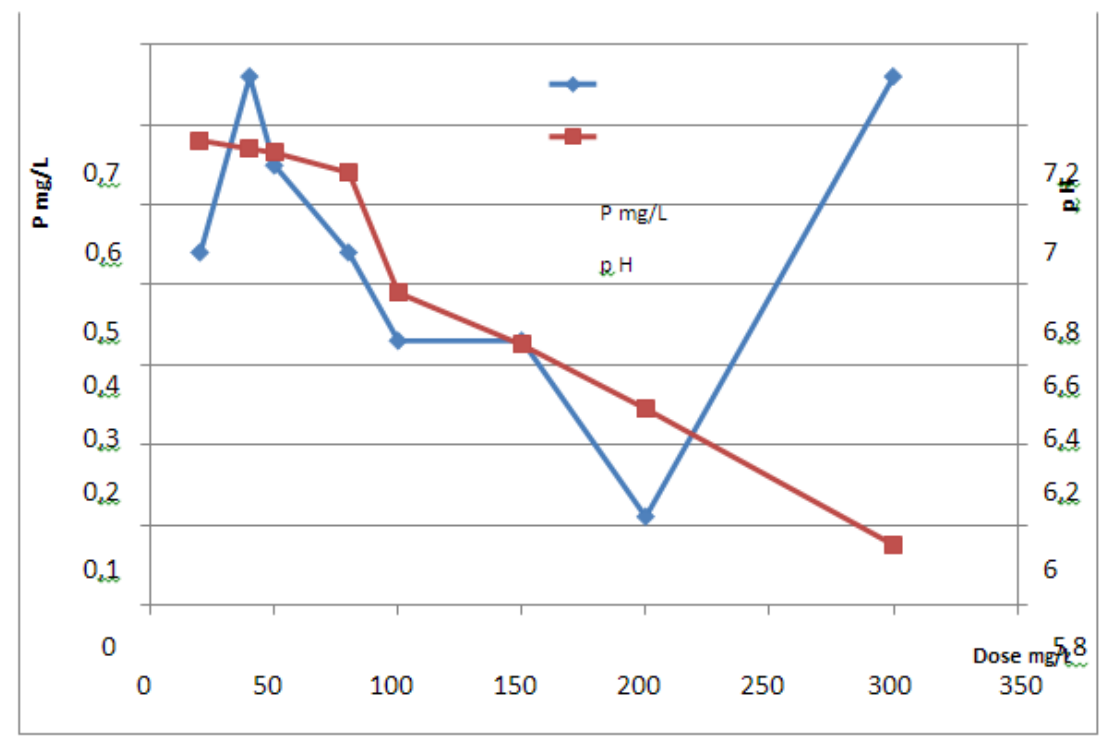

Figure 2-a. Dose Optimal of Ferric Chloride

The optimal dose of lime found in this test is between $500 \mathrm{mg} / 1$ and $600 \mathrm{mg} / 1$, Figure 3 -a and Figure 3-b clearly shows that the optimal dose represents the lowest concentration of phosphorus and Turbidity with an alkaline $\mathrm{pH}$ and therefore it is the highest removal efficiency.

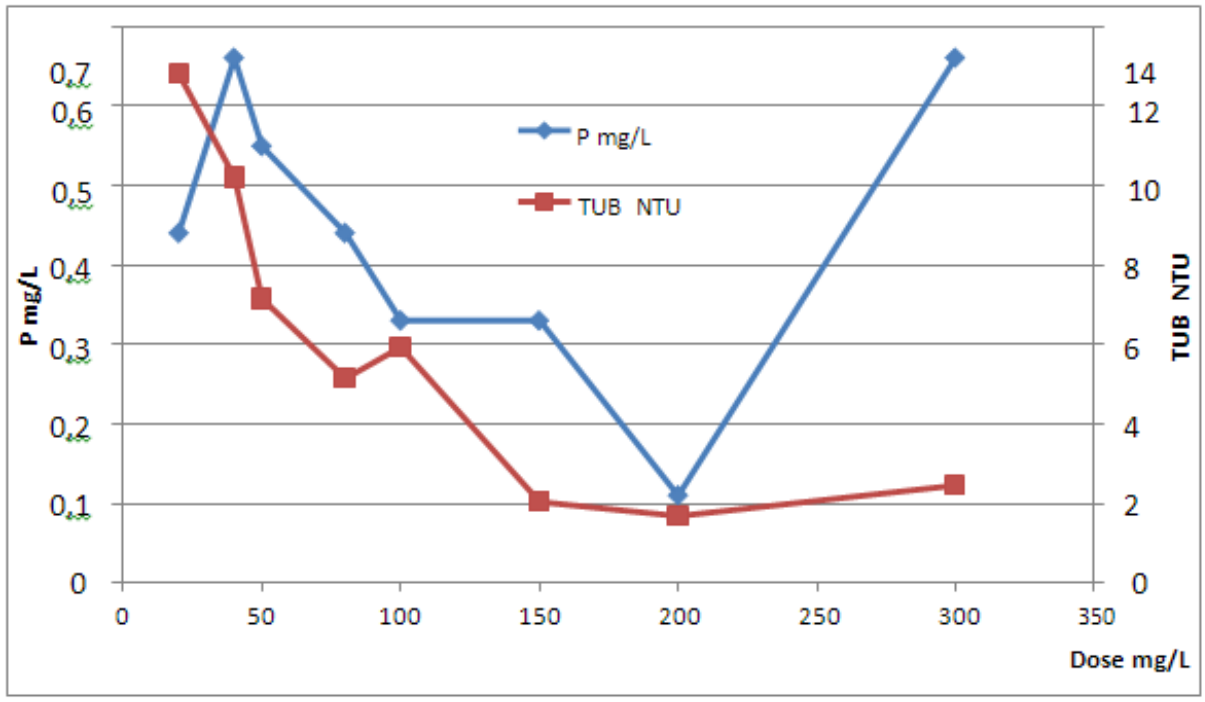

Figure 2-b. Dose Optimal of Ferric Cholride 


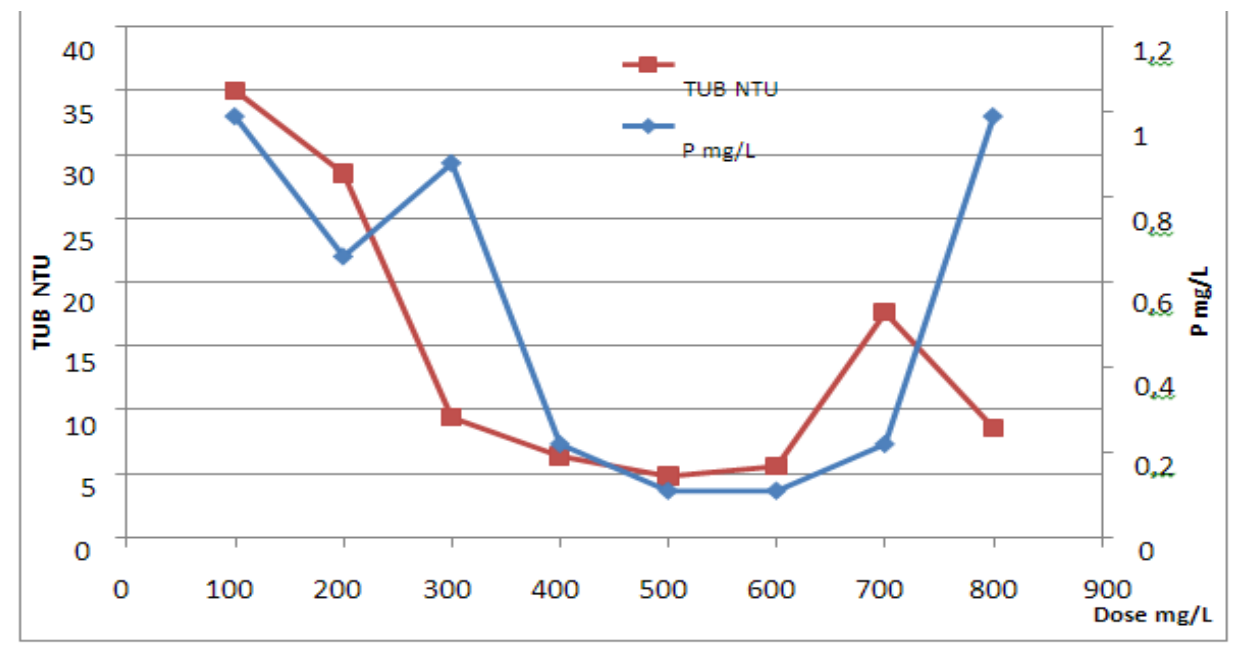

Figure 3-a. Dose Optimal of Lime

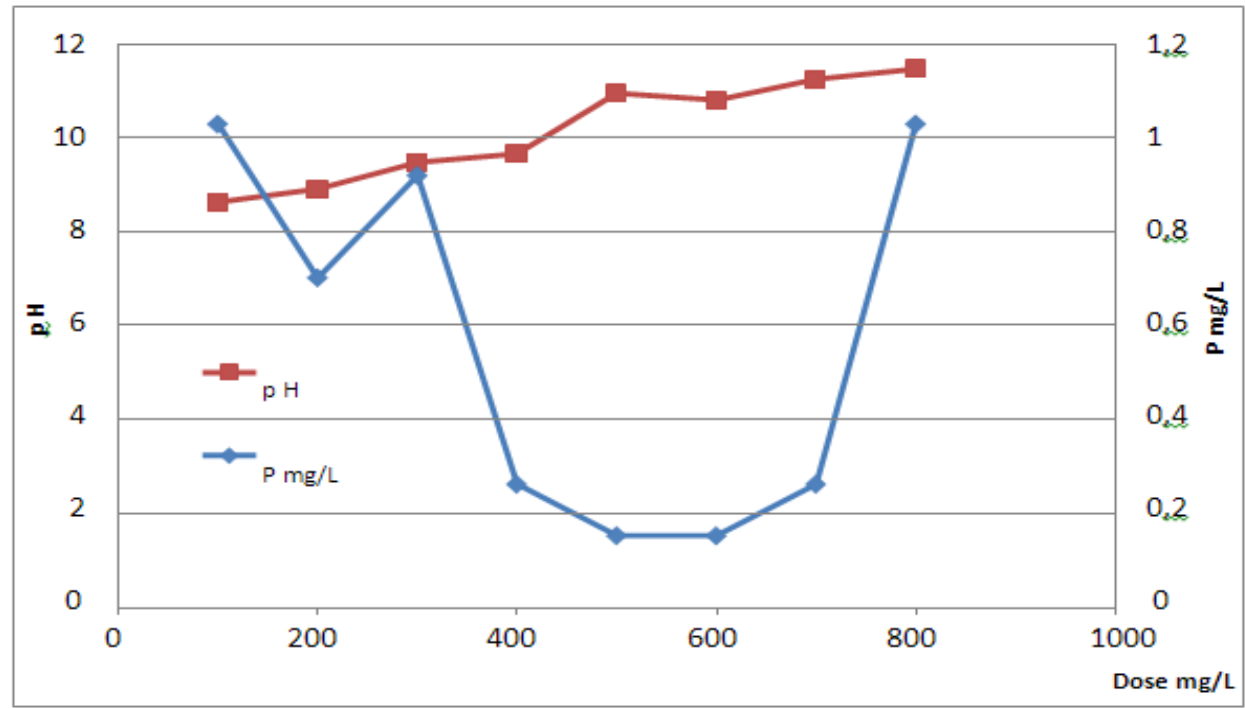

Figure 3-b. Dose Optimal of Lime

After using the optimal dose found in previous experiences of each type of coagulant, the following table summarizes the process of chemical treatment of waste water derived from the same site by measuring key parameters pollution standards prior and after the addition of this optimum dose exposed in Table 1.

Table 1. Parameters of Pollution Before and After Chemical Treatment

\begin{tabular}{llllll}
\hline Parameters & $\begin{array}{l}\mathrm{P} \\
(\mathrm{mg} / 1) \cdot 10\end{array}$ & $\begin{array}{l}\mathrm{DCO} \\
(\mathrm{mg} / 1)\end{array}$ & $\mathrm{p} \mathrm{H}$ & $\mathrm{T}^{\circ} \mathrm{C}$ & Turb (NTU) \\
\hline Rawsewage & 9,89 & 50,927 & 7,12 & 25 & 17,4 \\
$\begin{array}{l}\text { Wastewater after treatment } \\
\text { by sulfate aluminum }\end{array}$ & 2,19 & 5,009 & 6,5 & 25 & 2,08 \\
$\begin{array}{l}\text { Wastewater after treatment } \\
\text { by chloride ferric }\end{array}$ & 1,1 & 2,922 & 6,29 & 25 & 1,68 \\
$\begin{array}{l}\text { Wastewater after treatment } \\
\text { by lime }\end{array}$ & 1,09 & 3,756 & 10,4 & 25 & 4,78 \\
\hline
\end{tabular}


We have also determined the removal efficiency of each coagulant through measuring turbidity, DCO and total phosphorus. The following figure clearly demonstrates the efficacy of the chemical treatment. The figures below confirm the effectiveness of the chemical treatment in wastewater treatment, the treatment efficiency of DCO, is $95 \%$, phosphorus is $88 \%$, this result is very satisfactory and the majority of purification stations are adapting this treatment. However, the chemical treatment is known by the high rate of mud discharged into receiving waters, thus, another mode of treatment has been used known as the biological activated sludge treatment.

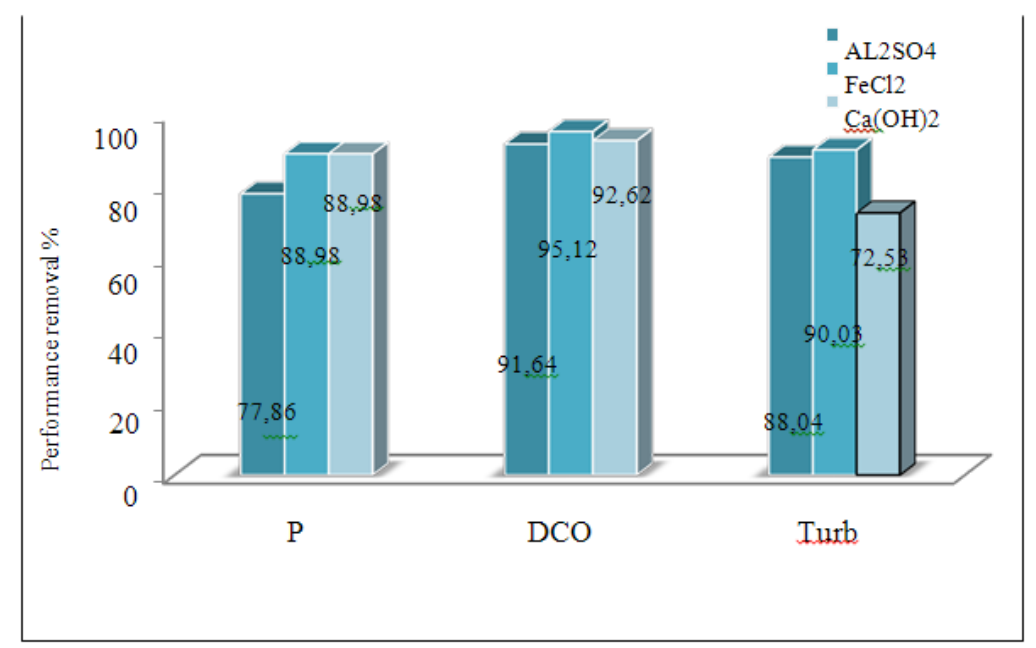

Figure 4. Performance of Chemical Treatment of Wastewater

Figure 5 (A) [2] demonstrates the abundance of orthophosphates in alkaline medium, which favors lime compared with other coagulants. These latter, as it is shown in Figure 6 , presents acid $\mathrm{pH}$ values showing only the acid forms of phosphorus. Besides being affordable, lime is considered an excellent disinfectant of wastewater that $\mathrm{s}$ why it $\mathrm{s}$ the most used coagulant for wastewater treatment.

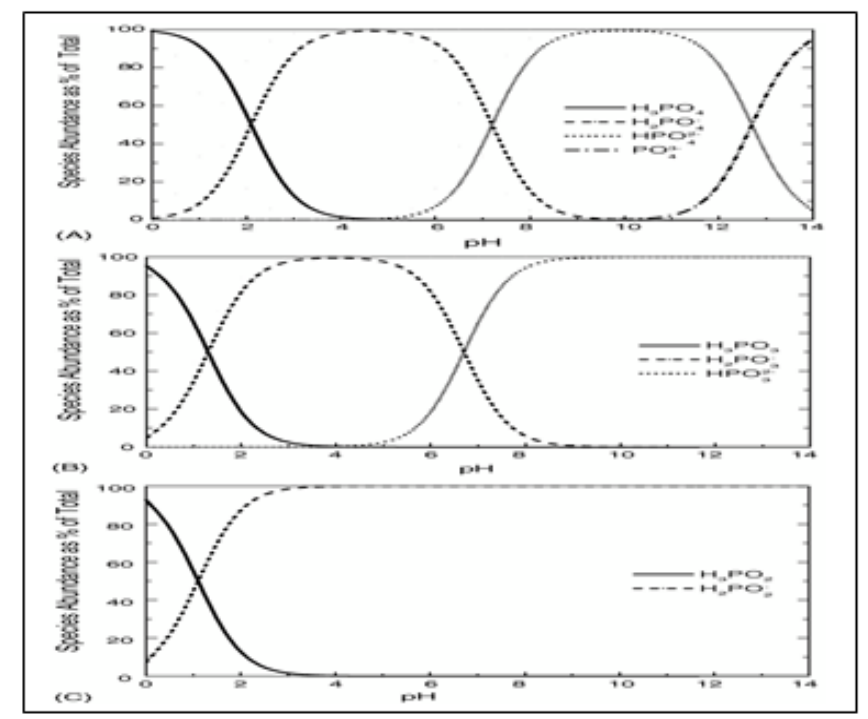

Figure 5. Correlation between Percentage of Species Abundance and pH 


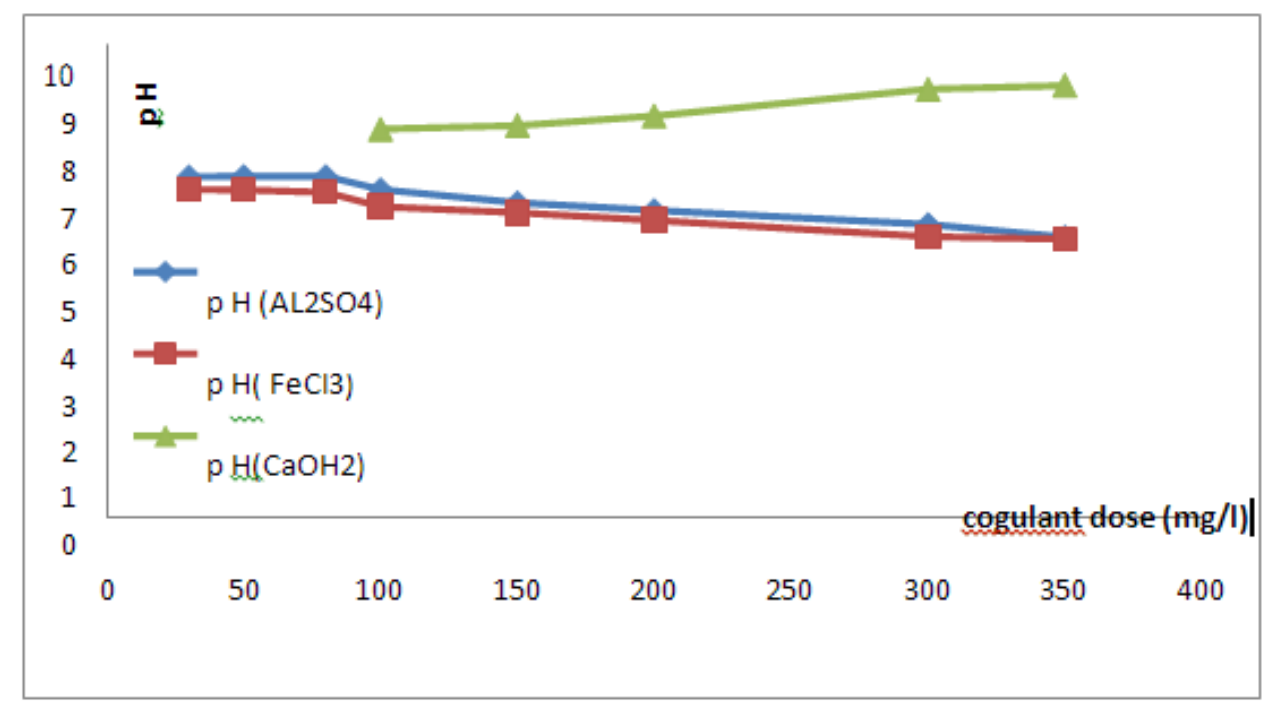

Figure 6. Behaviour of the pH According to the Dose of Coagulant

\subsection{Biological Treatment}

Similarly, the wastewater samples were collected in July from a wastewater treatment plant by activated sludge in the same city. They have been the subject of direct measurement of the temperature, $\mathrm{pH}, \mathrm{COD}$ and $\mathrm{P}$. The raw water is characterized by the following physicochemical parameters presented in the Table 2.

Table 2. Biological Treatment of Wastewater

\begin{tabular}{llll}
\hline & Before treatment & After treatment & $\begin{array}{c}\text { Treatment performance } \\
\%\end{array}$ \\
\hline DCO (mg/) & 519 & 201,623 & 61,15 \\
MES (mg/) & 996,22 & 450,12 & 54,81 \\
$\mathbf{P}(\mathbf{m g} / \mathbf{l}) . \mathbf{1 0} \mathbf{0}^{3}$ & 659 & 330 & 49,22 \\
\hline
\end{tabular}

The conventional urban wastewater treatment systems such as the treatment by activated sludge led to an efficacy of $60 \%$ DCO, and $49 \%$ of phosphorus, this result seems to be encouraging since this kind of treatment does not generate any deposit mud discharged into the river.

\subsection{Combined Treatment}

In order to reduce the amount of phosphorus in the wastewater discharged in the receiving environment (in our case it is the Mediterranean Sea), we opted for another form of treatment called combined treatment consisting of a biological treatment followed by a physico-chemical one. The obtained results are very satisfactory, we have determined the removal efficiency of each coagulant by measuring turbidity, COD and total phosphorus. The figure below (Figure 7) clearly shows the effectiveness of the combined treatment "Biological followed by a chemical treatment", the phosphorus removal efficiency increases from $51.16 \%$ to $83.45 \%$. 


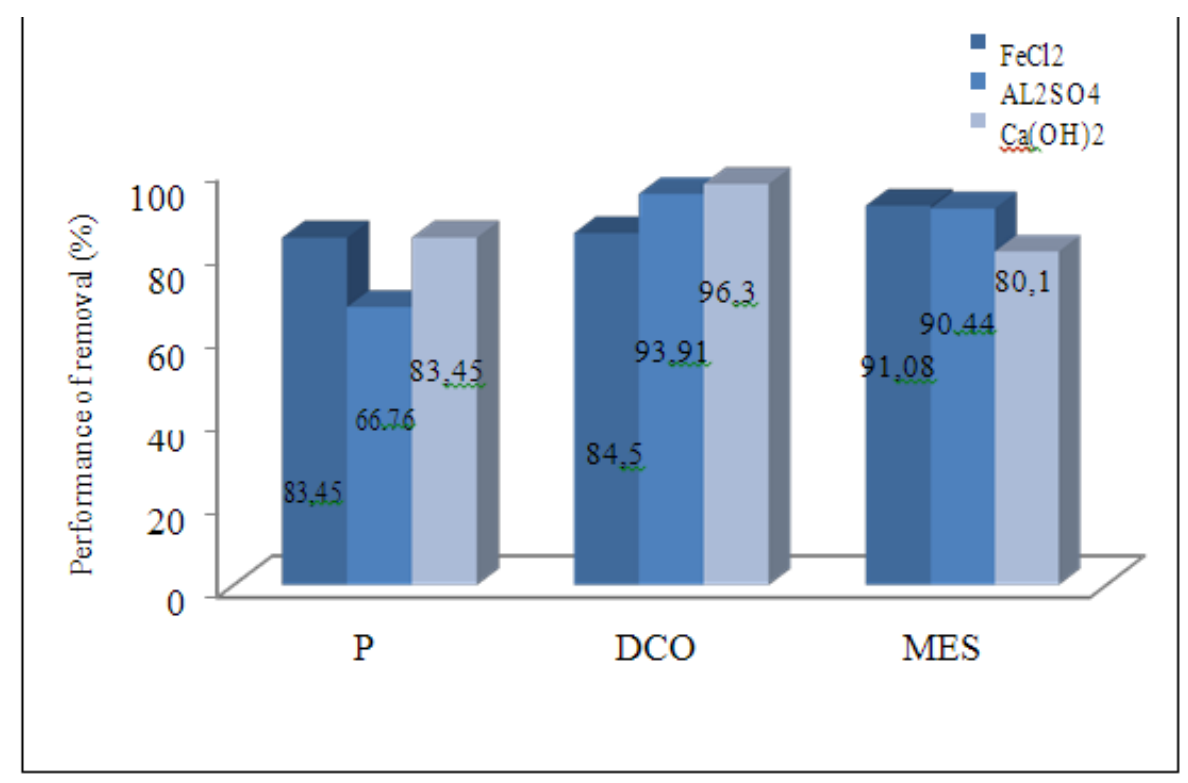

\section{Figure 7. Performance of Combined Treatment of Wastewater}

The chemical removal of phosphorus in waste water by the use of selected inorganic salts (ferric chloride, aluminum sulfate and lime) can be effective in a treatment plant in order to reduce the concentration of this nutrient discharged into receiving waters [13].

Lime is considered an excellent disinfectant and purifying of wastewater, as per ferric chloride we have obtained excellent phosphorus removal efficiency, but lime remains the most used because of its low price.

It is then possible, based on all tests on different types of removal treatments of phosphorus existing in domestic wastewater whether chemical or biological, that combined removal treatment enhances phosphorus removal and leads to a very satisfactory value, beside it significantly improves the performance of parameters pollution criteria (DCO, MES, P) [14].

\section{Conclusion}

The aim of this research work was to determine the treatment efficacy of each treatment type used, one deals with a purely chemical and purely biological treatment and another combines between the two. The results are satisfactory, we found a 96\% of COD, and $83 \%$ of phosphorus as removal efficiency through the combined treatment by using lime as a coagulant and a removal efficiency of the phosphorus is equal to $83 \%$.

The conducted treatment aimed mainly at the reduction of phosphorus discharges into the aquatic environment and therefore preserving the receiving environment whether lakes, rivers and seas from nutrients elements specifically phosphorus and consequently prevent environments through these treatments, the algae eutrophication and hinder eutrophication.

This study proved that even if the chemical treatment shows its effectiveness, the implementation of the combined one led to a much more phosphorus removal performance. Hence, we conclude that the combined treatment is the most appropriate treatment type for preserving the quality of the receiving environments

Through this research work, we incite the specialized authorities to implement such treatment which is economic and easy to adapt, in order to reduce wastewater pollution and why not reusing these treated wastewaters in the agricultural and fish breeding fields. 


\section{References}

[1] N. P. Cheremisinoff, "Biotechnology for waste and wastewater treatment", np, NOYES PUBLICATIONS, USA, (1996).

[2] V. H. Smith, G. D. Tilman and J. C. Nekola, "Eutrophication: impacts of excess nutrient inputs on freshwater", marine and terrestrial ecosystems, Environ. Poll, (1999).

[3] F. R. Spellman, "Hand book of water ans wastewater treatment plant operations", Lewis Publishers, Boca Raton London, (2003).

[4] F. Cabanes, "Dephosphatation des effluents: Précipitation et valorisation du phosphore", Thèse de doctorat, Institut National Polytechnique De Toulouse, (2006).

[5] S. Marryanto and A. P. Bayaseno, "Wastewater treatment for a sustainable future: Over view of phosphorus recovery", Applied Mechanics and Materials, Trans Tech Publications Switzerland, vol. 110-116, (2012).

[6] A. Stoddard, et al., "Municipal Wastewater treatment", Evaluation improvement in national.

[7] P. Cheremisinoff, "Handbook of water and wastewater treatment technologies", ButterworthHeinemann, (2002).

[8] G. Lépuration, "et le traitement des effluents (eau et air)", Ed TEC et DOC. water quality, John Wiley et sons, Inc., (2002).

[9] S. Rybicki, "Phosphorus removal from wastewater", A literature review, Advanced wastewater treatment, Plaza, Levlin, (1997).

[10] U. Wiesmann, I. S. Choi and E. M. Dombrowski, "Fundamentals of Biological Wastewater Treatment", WILEY- VCH Verlag GmbH \& Co. KGaA, Weinheim, (2007).

[11] U. Wiesmann, I. S. Choi and E. M. Dombrowski, "Fundamentals of Biological Wastewater Treatment", WILEY- VCH Verlag GmbH \& Co. KGaA, Weinheim, (2007).

[12] N. Bouallala, "L'expérience Algérienne En Matière D'épuration Des Eaux Usées", Science Lib Editions Mersenne, vol. 3, no. 111115, (2011).

[13] M. Henze, P. Harremoes, J. Jansen, C. La and E. Arvin, "Wastewater treatment: biological and chemical processes", Springer- verlag Berlin Heidelberg New York, ISBN: 3-540-58816-7, (1995).

[14] Reynolds, "The lakes Handbook", Lake restoration and rehabilitation, Black Well Publishing, vol. 2, (2005).

[15] J. Rodier, “Analyse de l'eau”, 7ème édition, édition Dunod, (1984).

[16] H. Roques, "Fondement théoriques du traitement des eaux", Tec et doc Lavoisier éd Paris, (1990).

[17] E. Tykesson, "Enhanced biological phosphorus removal", Doctoral Thesis, Department of Water and Environmental Engineering, Lund Institute of Technology, Lund University, Sweden, (2005).

[18] A. Takashi, et al., "Water Reuse", Issues, technologies and Applications, Metcalf et Edy, Inc, (2007). 
International Journal of $u-$ and $e-$ Service, Science and Technology Vol.8, No. 7 (2015) 